\title{
TRADUÇÃO INTERSEMIÓTICA OU ADAPTAÇÃO: ALGUNS APONTAMENTOS
}

\section{INTERSEMIOTIC TRANSLATION OR ADAPTATION: SOME NOTES}

Hugo Lenes Menezes

Instituto Federal de Educação, Ciência e Tecnologia do Piauí

Teresina, Piauí, Brasil

RESUMO: O processo de tradução é inerente à humanidade, a começar pela percepção circundante, através do que os dados da realidade, aportando ao intelecto, são traduzidos em signos, dos quais surgem a comunicação e o raciocínio. Na tradução intersemiótica (nomenclatura de Julio Plaza), ou seja, aquela que se refere a mais de uma semiose (termo de Charles Pierce), estamos diante da transposição de um sistema significante a outro: por exemplo, do sistema literário ao cinematográfico ou ao televisivo, atividade mais conhecida por adaptação. Entendida aqui a tradução tout court como (re)criação, a tradução intersemiótica, ou adaptação, é uma (re)criação de maior ousadia e complexidade, ou uma criação do próprio pelo alheio, como quer Marie Hélène Paret Passos, no seu livro $D a$ criação genética à tradução literária: uma interdisciplinaridade (2011). Uma ilustração do fato ocorre com as obras de arte verbal reeditadas mediante outros códigos estéticos, a exemplo de alguns rebentos da ficção seriada oitocentista (o romance-folhetim), como a telenovela, também conhecida como folhetim eletrônico. Assim sendo, no artigo ora apresentado, temos por objetivo fazer uma abordagem da relação entre algumas criações literária se a tradução intersemiótica ou adaptação, particularmente no que diz respeito a um escritor do Romantismo brasileiro, Bernardo Guimarães.

PALAVRAS-CHAVE: Tradução intersemiótica; Adaptação; Romance-folhetim; Folhetim eletrônico; Bernardo Guimarães

ABSTRACT: The translation is inherent in humanity, starting with the perception, through which data, when they get to the intellect, are translated into signs, of which arise communication and reasoning. In intersemiotic translation (nomenclature of Julio Plaza), that translation 
for more than one semiosis (a term of Charles Peirce), we face the transposition of a significant system to another, for example, the literary system for film or television, activity known for adaptation. Understood here the translation "tout court" as (re)creation, intersemiotic translation is (re)creating greater boldness and complexity, or according to Marie Hélène Paret Passos, in The genetic creation to literary translation: an interdisciplinary (2011), a creation of his own from the alien. An illustration occurs with the works re-edited by other creative codes, as some corms of serial fiction 19th century (the serial-novel), for example, the telenovela or electronic serial-novel. Therefore, here our goal is to show some written creations and intersemiotic translation or adaptation, particularly in the Brazilian writer Bernardo Guimarães.

KEYWORDS: Intersemiotic translation; adaptation; serial-novel; novel electronic; Bernardo Guimarães 


\section{CONSIDERAÇÕES INICIAIS}

A tradução é inerente à humanidade, a começar pela percepção circundante, através do que dados da realidade são traduzidos em signos no intelecto. A crítica estético-literária, enquanto leitura e (re)escrita especializada, representa uma modalidade de tradução, podendo ser essa, igualmente à crítica, tão criativa quanto a elaboração da obra de arte verbal ou não-verbal, apesar do lugar-comum de serem o crítico e o tradutor escritores frustrados, ideia contestada, no caso do crítico, por Bella Josef em $O$ jogo mágico, ${ }^{1}$ ao abordar o encantamento lúdico da palavra criativa, da qual são intérpretes o crítico e o tradutor.

$\mathrm{Na}$ tradução intersemiótica, temos a transposição de um sistema significante a outro, a exemplo do literário ao cinematográfico ou televisivo, atividade mais conhecida por adaptação. Entendida a tradução tout court como (re)criação, como meio legítimo de relação textual, e não somente como acesso secundário à literatura estrangeira, a tradução intersemiótica, ou adaptação, revela-se (re)criação ousada e complexa, ou, segundo Marie Hélène Paret Passos, ${ }^{2}$ criação do próprio pelo alheio.

Uma ilustração de tal prática acontece com produções escritas reeditadas mediante códigos rebentos da ficção seriada oitocentista, com alterações formais e sígnicas. Entre esses códigos, encontram-se as histórias em quadrinhos $(H Q)$. Exemplificando, citemos uns sofisticados desenhos de Matthias Schultheiss, Delírios cotidianos, releitura de contos de Charles Bukowski, lançada entre nós em 2008 pela L\&PM Editores.

Na coleção Quadrinhos $L \& P M$, também é estampada em 2016 a adaptação do romance Crime e castigo (1866), de Dostoievski, com tradução de Alexandre Boide, roteiro de David Mairowitz e ilustrações de Alain Korkos. Essa graphic novel, interessante releitura situada na Rússia atual, transcorre na São Petersburgo do século XX para o XXI. Trata-se, conforme The First Post, de "uma adaptação excelente [...]. Mairowitz faz ótimo trabalho ao modernizar a história [...] e o ilustrador Alain Korkos cria ambientações perturbadoras, cheias de maneirismos grotescos" (apud D’ANGELO, 2016, s.n). Para Grovel: Graphic Novel Reviews: "O uso de referências televisivas e da cultura pop na ambientação dá novo frescor à obra" (Op. cit., s.n).

Igualmente, mencionemos uma coleção da Editora Peirópolis, Clássicos em $H Q$, série composta por obras universais traduzidas para quadrinhos por cartunistas nacionais. Respeitando o original, tais adaptações incidem sobre a publicação in totum, ou segmentos. Tal é o caso da tradução intersemiótica da epopeia camoniana Os lusíadas (1572), transposta para $H Q$ em 2006 pelo cartunista Fido Nesti, que, autor da Introdução, mostra Camões contando sua história. Para elaborar os desenhos, Nesti se inspira em quadrinhos como Tintin,

\footnotetext{
${ }^{1}$ Cf. JOSEF, Bella. O jogo mágico. Rio de Janeiro: José Olympio, 1980.

${ }^{2}$ Cf. PASSOS, Marie-HelénèParet. Da criação genética à tradução literária: uma interdisciplinaridade. Vinhedo: Horizonte, 2011.
} 
de Hergé, e em filmes como No coração do mar (2015), dirigido por Ron Howard e adaptado de Moby Dick (1851), de Melville. Os Clássicos em HQ também incluem, entre outros, A divina comédia (1472), de Dante, por Piero e Giuseppe Bagnariad; $O$ auto da barca do inferno (1516), de Gil Vicente, por Laudo Ferreira; e A morte de Ivan Ilitch (1886), de Tolstói, por Caeto.

$\mathrm{Na}$ arte verbal brasileira, o sítio eletrônico Pensar Contemporâneo traz, de 2011, a tradução intersemiótica de um poema dramático de João Cabral de Melo Neto. Miguel Falcão transpõe, para HQ animada, Morte e vida severina (1955). Reverenciando o original, a animação sonoriza da em 3D confere vida aos seres fictícios daquele auto de natal. Também na década de 2000, Grandes Clássicos em Graphic Novel nomeiam uma coleção de quadrinizações de romances. Publicada pelos selos Agir e Desiderata, compõe-se dos seguintes volumes, seguidos de autores e quadrinistas: $O$ alienista (1882), de Machado de Assis/Fábio Moon e Gabriel Bá; O pagador de promessas (1959), de Dias Gomes/Eloar Guazzelli Filho; Triste fim de Policarpo Quaresma (1915), de Lima Barreto/Edgar Vasques e Flávio Braga; Memórias póstumas de Brás Cubas (1881), de Machado de Assis/João Batista Melado e Wellington Srbek; Os sertóes: a luta (1902), de Euclides da Cunha/Carlos Ferreira e Rodrigo Rosa; Luciola (1862), de José de Alencar/Ricardo Rocha e Maria Helena Rolante; $A$ terceira margem do rio (1962), de Guimarães Rosa/Maria Helena Rouanet e Thaís dos Anjos; além de O castelo (1926), de Franz Kafka/Carlos Ferreira.

Outra destacada produção de graphic novels, por adaptadores nacionais nos anos 2000, reconhecemos na Coleção Shakespeare em Quadrinhos da Editora Nemo, tendo à frente Wellington Srbek, que coordena sete volumes. São eles e seus quadrinistas: Romeu e Julieta (1597 - Marcela Godoy e Roberta Pares); Sonho de uma noite de verão (1600 -Lillo Parra e Wanderson de Souza); Otelo, o mouro de Veneza (1622 - Jozz e Akira Sanoki); A tempestade (1623 - Lillo Parra e Jefferson Costa); Macbeth (1623 - Marcela Godoy e Rafael Vasconcellos); Hamlet, príncipe da Dinamarca (1601-Wellington Srbek e Alex Shibao); e Rei Lear (1623 - Jozz e Octavio Cariello).

Literatura brasileira em quadrinhos constitui coleção de romances gráficos do Grupo Escala de Publicações, com quadrinizações, entre 2004 e 2014, de clássicos literários nossos. Eis alguns títulos dos volumes, seus autores e adaptadores: $O$ cortiço (1890), de Aluísio Azevedo/Ronaldo Antonelli (roteiro) e Francisco Vilachã (desenhos); Memórias de um sargento de milícias (1854), de Manuel Antônio de Almeida/Índigo (roteiro) e Bira Dantas (desenhos); O Ateneu (1888), de Raul Pompeia/Ronaldo Antonelli (roteiro) e Bira Dantas (desenhos); Inocência (1872), de Visconde de Taunay/ Ronaldo Antonelli (roteiro) e Francisco Vilachã (desenhos); e A moreninha (1844), de Joaquim Manuel de Macedo/Maria Sonia Barbosa (roteiro) e Sebastião Seabra (desenhos). A Edição Maravilhosa, publicada mensalmente pela Brasil-América Limitada (EBAL), é uma coleção de quadrinhos nos moldes das revistas americanas Classics Illustrated e Classic Comics. Tanto a Classics Ilustrated, quanto a Edição Maravilhosa dão a lume a modalidade HQ baseada em obras literárias. Vejamos uns números de tal publicação da EBAL: $O$ guarani (1857), de José de Alencar ( $\mathrm{n}^{\mathrm{o}}$ 24/1956); Cabocla (1831), de Ribeiro Couto ( $\mathrm{n}^{\circ}$ 86/1954); Menino de engenho 
(1932), de José Lins do Rego ( $\mathrm{n}^{\circ}$ 100/ 1955); Senhora (1875), de José de Alencar $\left(\mathrm{n}^{\circ}\right.$ 120/1956); Sinhá moça (1950), de Maria Dezonne Pacheco Fernandes ( ${ }^{\circ}$ 144/1957/1986); A muralha (1954), de Dinah Silveira de Queiroz (nº 146/1957); bem como Mar morto (1936), de Jorge Amado ( $\mathrm{n}^{\circ}$ 186/1960).

Como spin-off (obra derivada) da coleção supracita e pelo mesmo selo, surge outra coleção, Literatura mundial em quadrinhos, da qual mencionemos $O$ crocodilo (1865), conto de Dostoievski adaptado por Jorge Guidacci em 2011. Como mangás, quadrinhos à japonesa, pelo selo editorial brasileiro New Pop no decênio de 2000, referimos os títulos seguintes, com autores e adaptadores: Helena (1876), de Machado de Assis/Simone Beatriz; As aventuras de Alice no país das maravilhas (1865), de Lewis Carroll/Sakura Kinoshita; Grimms mangá (Contos de Grimm - 1812), de Jacob e Wilhelm Grimm/Kei Ishiyama. Como produção avulsa de selos diversos nas edições brasileiras, elencamos: Sharaz-decontos de "As mil e uma noites" (séc. IV d.C), Anônimo/Sergio Toppi, pela Figura Editora em 2016; As aventuras de Pinóquio (1883), de Carlo Collodi/Winshluss, pela Globo em 2013; Dom Casmurro (1900), de Machado de Assis/Felipe Greco (roteiro)/Mário Cau (arte), pela Devir Livraria em 2013; Jubiabá (1935), de Jorge Amado/Spacca, pela Quadrinhos na Cia em 2009; Clara dos Anjos (1948), de Lima Barreto/Wander Antunes (roteiro)/Lelis (arte), pela Quadrinhos na Cia em 2011; Grande sertão: veredas (1956), de Guimarães Rosa/Eloar Guazzeli Filho (roteiro)/Rodrigo Rosa (arte), pela Globo em 2014; e Dois irmãos (2000), de Milton Hatoum/Fábio Moon/Gabriel Bá, pela Quadrinhos na Cia em 2015. Todos os clássicos até aqui aludidos também possuem adaptação para cinema e/ou televisão.

Ainda dos clássicos literários, é lançado em 2017, pelo roteirista e cineasta Ari Folman e pelo ilustrador David Polonsky, quadrinhos de $O$ diário de Anne Frank (1947), transformado antes na graphic novel intitulada Anne Frank: a biografia ilustrada (2010) e a sair em adaptação cinematográfica em 2019. De Tchekhov, Yuri Martins Oliveira traduz entre nós, para um projeto entre a publicadora Story Max, a multinacional de biotecnologia Novozymes e um integrante do Sistema S, SESI-Paraná, o conto "Ostras" (1884), que recebe tratamento digital, quase surrealista, sob forma de livro-aplicativo ilustrado, com efeitos sonoros, animação e interatividade, disponível em português, inglês e espanhol, para tablets, smartphones IOS e Android. Outro russo, Tolstói, tem sua obra Guerra e paz (1869) vertida para produção interativa, mediante aplicativo inglês, Live pages (2017), de especialistas do Tolstoy Digital Group. A Story Max reconta também a história curta de terror "Frritt-Flacc" (1884), de Jules Verne, e cria o aplicativo Frankie for kids (2012-2014), sobre o protagonista de Frankenstein (1818), de Mary Shelley.

A plataforma digital Open culture noticia adaptações de textos literários para o cinema animado, inclusive compilando diversos títulos. Vejamos alguns selecionados: "A caverna", em A república (séc. IV a.C), de Platão, já transformada numa animação em argila, com fotografias de John Grisby, em versão de 1973 conta com narração de Orson Welles e arte surrealista de Dick Oden; Édipo rei (427 a.C), de Sófocles, numa inusitada tradução intersemiótica de John Wishnow em 2004, com animação cujos personagens são vegetais; 
Diários de Kafka (1910-1923) transformam-se em curta-metragem animado por Piotr Dumala; $O$ velho e o mar (1952), de Hemingway, é reescrito e dirigido para tal modalidade cinematográfica em 1999, mediante técnica envolvendo pintura em pastel de óleo sobre vidro; e A metamorfose do Sr. Samsa corresponde à adaptação em preto e branco da obra kafkiana de 1915 com técnica em que areia é colocada sobre tela iluminada e manipulada pela animadora Caroline Leaf.

Flertando com a sétima arte, a HQ origina as fotonovelas, que, com os quadrinhos, roubam do romance-folhetim páginas em revistas. Esse gênero romanesco se insinua via fita-em-série americana e também é publicado como radionovela e novela de televisão, ou folhetim eletrônico. Semelhante quadro nos recorda um mestre do conto ocidental e um dos maiores nomes da novelística universal: Maupassant. Seu romance Bel-ami (1885), impiedoso retrato do duvidoso universo da nascente imprensa moderna, completando Ilusões perdidas (1843), de Balzac, inspira telenovela brasileira homônima (1972) da TV Tupi e corre perto do padrão folhetinesco, vindo ademais a integrar a coleção de bestsellers "Grande Sucessos" (1980-1983) da Editora Abril.

Nesse âmbito do folhetim, o mais célebre e adaptado romance europeu para o teatro, cinema e televisão, identificamos em $O$ conde de Monte Cristo (1844), de Alexandre Dumas, levado ao ar, em 1966, como telenovela da Rede Globo, sob o título sensacionalista de Eu compro essa mulher. Nos Oitocentos, só costuma haver plateia representativa para artes cênicas quando se encontra em cartaz O conde de Monte Cristo ou As duas órfãs (1875), de A. P. Dennery, sendo também necessário, para aumentar a venda e leitura do jornal, anexar-lhe o folhetim de Dumas.

Bem popular mostra-se a série Memórias do diabo (1837), de Fréderic Soulié, no Journal dês Débats da Cidade Luz. E paradigma do gênero em questão, no Ocidente, revelam-se Os mistérios de Paris, inspirados em Les deux serruriers (1841), melodrama de um folhetinista de bravas ideias sociais, Félix Pyat, e estampados, naquele mesmo periódico, entre 1842 e 1843, por Eugène Sue. Noutras formas de cultura de massas, prolongam-se Os mistérios de Paris, com cinco adaptações cinematográficas francesas entre 1911 e 1962, uma italiana em 1957 e uma série de TV franco-alemã em 1980.

Com origem no teatro, em um caminho inverso, o folhetim Os mistérios de Paris, na sede do Brasil imperial, é adaptado para artes cênicas como um drama, A família Morel, em 1852, e em1859, naquele local, é montada outra peça baseada no romance: o drama em três atos e ornado de música $A$ família Morel dos Mistérios de Paris. Também de ressonância mundial,... E o vento levou (1936), best-seller à maneira de folhetim novelesco, da americana Margaret Mitchell, recebe tradução intersemiótica para o cinema, lançada em 1939 nos Estados Unidos, e uma versão em 2008 para o teatro musical, fronteiriço à ópera e ao cabaré. Música e letra do espetáculo, apresentado em Londres, são de Margaret Martin e o libreto é adaptado por Sir Trevor Nunn.

De uma compatriota de Margaret Mitchell, qual seja, Harriet Stowe, e publicado em capítulos no jornal National Era, de Washington, entre 1851 e 1852, o folhetim impresso A cabana do pai Tomás, já transposto ao teatro e cinema, dá origem a uma adaptação brasileira de Hedy Maia, Péricles Leal e 
Walter Negrão, para folhetim eletrônico homônimo, telenovela ou, como classificada nos Estados Unidos, série dramática, exibida pela Rede Globo de Televisão, entre julho de 1969 e março de 1970.

Ainda em caminho inverso, em nosso país, Mauro Alencar, também autor de A Hollywood brasileira: panorama da telenovela no Brasil (2002), faz adaptações de folhetins eletrônicos para romances impressos da coleção de livros Grandes Novelas, lançada pela Editora Globo em 2007. São as seguintes as telenovelas adaptadas: Selva de pedra (1972), de Janete Clair; O bem-amado (1973), de Dias Gomes; Pecado capital (1975-1976), de Janete Clair; Roque santeiro (1985-1986), escrita por Dias Gomes e Aguinaldo Silva, baseada na peça teatral O berço do herói (1963), do primeiro; e Vale tudo (1988-1989), de Gilberto Braga, Aguinaldo Silva e Leonor Bassères.

Outras semelhantes coleções de livros são As Grandes Telenovelas e Campeões de Audiência: Telenovelas, ambas da década de 1980. A primeira é uma coleção da Rio Gráfica e Editora em 1985. As adaptações para produções impressas são realizadas pelos próprios telenovelistas ou outros profissionais, sendo 12 os livros lançados e as telenovelas adaptadas: Irmãos Coragem (19701971), de Janete Clair; O bem-amado (1973), de Dias Gomes; Carinhoso (19731974), de Lauro César Muniz; Escalada (1975), de Lauro César Muniz; Pecado capital (1975-1976), de Janete Clair; Anjo mau (1976), de Cassiano Gabus Mendes; Locomotivas (1977), de Cassiano Gabus Mendes; Dancin'Days (19781979), de Gilberto Braga; Pai herói (1979), de Janete Clair; Marron-glacé (19791980), de Cassiano Gabus Mendes; Água viva (1980), de Gilberto Braga; e Louco amor (1983), de Gilberto Braga.

A coleção de romances impressos Campeões de Audiência: Telenovelas é lançada pela Editora Globo entre 1987 e 1988. As adaptações são realizadas do mesmo modo e as telenovelas adaptadas são: Irmãos Coragem (1970-1971), de Janete Clair; Bandeira 2 (1971-1972), de Dias Gomes; Escalada (1975), de Lauro César Muniz; Pecado capital (1975-1976), de Janete Clair; Anjo mau (1976), de Cassiano Gabus Mendes; Locomotivas (1977), de Cassiano Gabus Mendes; Dancin'Days (1978-1979), de Gilberto Braga; Pai herói (1979), de Janete Clair; Água viva (1980), de Gilberto Braga; Guerra dos sexos (1983), de Sílvio de Abreu; Roque santeiro (1985-1986), de Dias Gomes; e Roda de fogo, (1986 1987), de Lauro César Muniz.

De novo em caminho inverso, a Rede Globo de Televisão empreende ação transmídia para promover uma telenovela de época, exibida às 18 horas e intitulada Novo Mundo (2017), de Thereza Falcão e Alessandro Marson. Mediante tal ação, no Gshow, portal de entretenimento da emissora, o telespectador pode ler o romance brasileiro de mesmo título da telenovela, romance o qual é o segundo livro que, no folhetim eletrônico em tela, o personagem Anna Milmann elabora.

Nesse seu segundo livro, o nomeado personagem narra aventuras amorosas de Emily White, jovem inglesa inspirada na própria Anna Milmann. Na vida real, a obra literária é escrita pela editora de conteúdo Elaine Teixeira, por meio da adaptação do folhetim eletrônico para romance. Num admirável mundo novo, toda semana, às segundas-feiras, disponibilizam-se dois capítulos do livro para 
download no aplicativo do Gshow. Ao todo, são trinta capítulos, cuja publicação vai até ao final da telenovela, em setembro de 2017.

Igualmente no Brasil, a mais famosa criadora de folhetins eletrônicos, Janete Clair, também autora de folhetins radiofônicos e de fotonovelas, chega a escrever, para a revista Manchete, no Rio de Janeiro (RJ), de 22 de março de $1980\left(\mathrm{~N}^{\circ} 1.487\right)$ a 24 de maio de $1980\left(\mathrm{~N}^{\circ} 1.496\right)$, um romance-folhetim, Nenê Bonet, publicado em livro e adaptado para o teatro.

\section{OS FOLHETINS BERNADIANOS E A TRADUÇÃO INTERSEMIÓTICA OU ADAPTAÇÃO}

Bernardo Guimarães compõe sua ficção narrativa conforme o espírito do folhetim, embora publique apenas dois romances parcelados em periódicos: $O$ ermitão de Muquém, em $O$ Constitucional, de Ouro Preto (MG), entre 1866 e 1867, saindo em livro em 1869, e $O$ índio Afonso, em A Reforma, do Rio de Janeiro (RJ), em 1872, saindo em livro em 1873.

Em Cidades mortas (1919), Monteiro Lobato indica os hábitos de leitura de paulistas do Vale do Paraíba, hábitos esses dos quais Bernardo Guimarães faz parte, ao lado de mestres europeus do romance-folhetim. No comentário lobatiano, o autor relembra que, naquelas cidades mortas, circulam três obras respeitáveis e manchadas pelo manuseio durante leituras e releituras de consecutivas gerações: La mare d'Auteuil (1852), de Paulo de Kock, para quem sabe francês; volumes incompletos de As proezas de Rocambole (1853), de Ponson du Terrail, para o deslumbramento feminino; e $A$ ilha maldita (1879), de Bernardo Guimarães, para encanto de todo o público.

Vimos, a saber, que, mesmo entre os romances bernardianos lançados diretamente em livro, alguns deles, como $O$ seminarista (1872) e A escrava Isaura (1875), são republicados em periódicos: o primeiro no Jornal do Pará, Diário de Belém, Liberal do Pará e na Folha do Norte, retomando a ficção seriada; o segundo, ao menos em parte, na folha baiana Gazeta da Tarde, em cuja edição de 23 de junho de 1881 localizamos o capítulo XIX da narrativa da cativa branca. Tal fato constitui uma maneira de aproximar o público de uma produção literária que pode não circular amplamente à época em cidades como Belém e Salvador, capitais de estados periféricos. Mas até num jornal como a Gazeta de Campinas- no interior de São Paulo, nosso mais desenvolvido estado, encontramos, de 1869 a 1887, reedições em folhetins, inclusive póstumas (conforme concluímos pelas datas), de livros de Bernardo Guimarães, juntamente a ícones do gênero em foco, como Alexandre Dumas e Ponson du Terrail.

No tocante a Bernardo Guimarães, mencionemos que, no final feliz de seu romance-folhetim Rosaura, a enjeitada (1883), após a morte dos personagens Morais e Damázio, os dois pares de noivos, Conrado e Adelaide, Carlos e Rosaura, vão juntos ao altar, encerrando o livro numa nota familiar de dois casamentos e dois funerais. Diante do happy end da história, com ação para lá de movimentada, haja vista suas reviravoltas e coincidências rocambolescas, 
perpassadas por dose generosa de bom humor, acorre-nos à memória o filme britânico Quatro casamentos e um funeral (1994), comédia romântica de Mike Newell. Rosaura, a enjeitada, privilegiando o discurso direto, momentos cinematográficos, hollywoodianos avant la lettre, e lances teatrais, também encaramos como verdadeira comédia romântica.

As narrativas de Bernardo Guimarães sempre se prestam a adaptações ou traduções intersemióticas, diferentemente de muitas obras literárias cuja adaptação para outros códigos estéticos é quase inviável, como Em busca do tempo perdido (1913), de Proust, e Ulysses (1922), de Joyce. O romance bernardiano $O$ seminarista transforma-se em filme brasileiro de 1976 e em quadrinhos em 1955. Igualmente, outros romances, como $O$ garimpeiro (1872), adaptado para o teatro em 1896, bem assim para o cinema nacional em 1920, e $A$ escrava Isaura, com duas versões cinematográficas (1929 e 1949) e adaptado para a Edição Maravilhosa da EBAL em 1954, são também reeditados, como vemos, mediante um dos rebentos do folhetim impresso, precisamente as $H Q s$.

Aliás, existem críticos que, analisando todas as tramas novelescofolhetinescas de Bernardo Guimarães, caracterizam-nas como um novelo de lances que podem originar interessantes histórias em quadrinhos; como passível, também, de tradução intersemiótica para tal código criativo. No Medievo, novela é sinônimo de entrecho, enredo, narrativa trançada, como a história de cavalaria, que bem merece carregar o sentido de novelo. Quanto à perfeita viabilidade de adaptação da novelística bernardiana para quadrinhos, Hélio Guimarães, em sua introdução às Lendas e romances (1871), de nosso escritor, chega a afirmar que:

Em alguns momentos, a carga visual com que se descrevem as ações dos personagens [...] remete também às modernas histórias em quadrinhos e aos desenhos animados, tamanho o exagero das ações, que nenhum ser de carne e osso seria capaz de desempenhar e suportar. É a esse universo que parece pertencer a movimentação do cavalo do herói do conto "Uma história de quilombolas", que trepava rochedos, saltava buracos e descia abismos com a presteza e agilidade do cabrito montês, equilibrando-se com as quatro patas num espaço tão exíguo que mal acreditaríamos caber ali um rato (GUIMARÃES, 2006, p. XIII).

Como dissemos, os quadrinhos flertam com o cinema e, particularmente no tocante ao romance-folhetim A escrava Isaura, ilustrado com desenhos de Antônio Eusébio para a revista Cinemin, já considerada entre nós a melhor sobre a sétima arte, vimos que essa obra bernardiana, enquanto filme, alcança mais de uma vez a telona. Igualmente, declaramos que tal tipologia romanesca também vem a público como radionovela e novela de televisão. Rosaura, a enjeitada recebe tradução intersemiótica para radionovela, embora sem atingir o estrondoso efeito midiático de A escrava Isaura. Na Cidade Maravilhosa, a Rádio Nacional, radiofoniza em 1955 Rosaura, a enjeitada com o título de Escrava do amor, numa admirável adaptação do dramaturgo, diretor, produtor e roteirista de cinema brasileiro Oduvaldo Vianna. 
A Editora Migalhas, em 2014 disponibiliza, em página eletrônica, síntese adaptada de Rosaura, a enjeitada, tanto com palavras de quem faz a condensação, quanto com termos exatos do autor da narrativa, enquanto curiosa trama jurídica na sessão "Novela em migalhas". Os editores recontam o longo enredo em capítulos reduzidos e renomeados, como mesmo suspense e desenlace, mas tomando a liberdade de trocar nomes de personagens. E, como na adaptação de $A$ moreninha, de Macedo, para telenovela de 1975, Marcos Rey substitui o nome de Joaquina por Quininha, e Teixeira Filho, em 1981, na tradução televisiva do romance Ciranda de pedra (1954), de Lygia Fagundes Telles, substitui o nome de Conrado por Luís Carlos, julgamos que algumas figuras de Rosaura, a enjeitada, na transposição para site, não se chamam mais conforme o original por talvez os novos nomes possuírem hoje maior circulação. Assim, Rosaura passa a Joana e Conrado, a Frederico.

Como Rosaura, a enjeitada, para o rádio é transposta $A$ escrava Isaura, também alvo das atenções da teledramaturgia: primeiramente numa adaptação em 1961 da TV Itacolomi. Em 1976, pela Rede Globo, recebe adaptação de Gilberto Braga, uma das telenovelas brasileiras de maior sucesso no exterior, conferindo internacionalização ao literato ouro-pretano, cujo livro sobre Isaura é traduzido para vários idiomas, como alemão, francês, chinês, húngaro e indonésio, e o romance $O$ garimpeiro, bem como parte de "Uma história de quilombolas" (1871), encontram-se traduzidos/adaptados linguisticamente para o francês por Victor Orban.

Demonstrando outras alterações ocorridas numa tradução intersemiótica, no caso a transposição do sistema significante do folhetim impresso ( $A$ escrava Isaura) para o sistema significante eletrônico-televisivo, Nilson Xavier, especialista em teledramaturgia e, juntamente com Mauro Alencar, um dos autores do Almanaque da telenovela brasileira (2007), assinala que:

No romance de Bernardo Guimarães, Isaura só encontra o amor em Álvaro a dois terços da história. Gilberto Braga, o adaptador do livro, criou então o personagem Tobias, para evitar tanto tempo de Isaura no ar sem um interesse afetivo. Tobias sumiu da trama em um entrecho folhetinesco magistral: foi morto em um incêndio, pelo vilão Leôncio. Nesse mesmo incêndio, pensando tratar-se de Isaura, Leôncio acaba por assassinar a própria esposa, Malvina. No romance, o destino de Malvina não é tão trágico: ela abandona Leôncio. A cena do incêndio na cabana foi uma das mais marcantes da novela (XAVIER, 2017, s.n).

Vinte e nove anos depois daquelas transposições para $o$ folhetim eletrônico, A escrava Isaura é objeto de outra bem sucedida tradução televisiva, por Tiago Santiago na Rede Record, onde esse romance ainda inspira, a Gustavo Reiz, a telenovela Escrava mãe (2016). Antes e depois das traduções televisivas, A escrava Isaura ganha adaptações para o teatro, no qual se firmam as raízes do folhetim, via melodrama, incluindo o telenovelístico, chamado melodrama em episódios mutantes. Nessa esfera, "Jupira", novela impressa da bernardiana obra 
História e tradições da província de Minas Gerais (1872), é recriada em libreto de ópera nacional, com partitura do maestro Francisco Braga.

Tanto o gênero melodramático quanto o folhetinesco nascem sob a condição de porta-vozes da ideologia da Revolução Francesa, cúmplice da teatralidade exagerada e do espetacular, como demonstra sua fase de terror. Referente à história de Isaura, a mais popular de seu autor, também repentista, temos notícia de um folheto de cordel escrito por Caetano Cosme da Silva, folheto esse inspirado num drama de circo, calcado na versão em folhetim eletrônico da Rede Globo para o romance em tela.

Em 2001, tal narrativa literária ganha versão infanto juvenil para uma coleção de clássicos universais adaptados para estudantes secundaristas, sendo recontada com palavras da pedagoga Guila Azevedo e código visual das ilustrações de Cristina Burger. Em 2002 é contemplada com adaptação ao teatro por Walter Daguerre, de onde devermos lembrar que são, sobretudo literatos voltados às artes dramáticas, como Alexandre Dumas, que aperfeiçoam o procedimento folhetinesco com total noção do corte de capítulo, artifício para levar o receptor a buscar a continuação no próximo número do jornal ou fascículo.

Esse recurso teatral costuma apresentar desdobramentos inesperados, com a intervenção do acaso para socorrer ou complicar a vida do personagem. Propagando-se como marca do folhetim, inclusive trazendo ao romance outra dinâmica, certo equilíbrio e simetria à amarração dos capítulos, os coups de théâtre (lances ou golpes teatrais) já estão implícitos nos contos de Sherazade, maga de As mil e uma noites (séc. IV d.C), tidas por Jorge Luís Borges como a primeira novela em fascículos, ou, por que não dizer, como o primeiro folhetim.

Muito utilizado por Bernardo Guimarães, especialmente em Rosaura, a enjeitada, o corte, interrupção da ação num momento de grande conflito, ou a técnica do gancho na linguagem televisiva do folhetim eletrônico, é assimilado por ficções romanescas, cinema, $H Q$, fotonovela, radio novela, tele novela e pela dita face novela, a partir dos coups de théâtre, do melodrama e do dramalhão.

Para concluir, retomamos o melodrama como origem do folhetim e verificamos que os romances bernardianos estão, com semelhante forma cênica, em sintonia, enquanto espécie narrativa e conforme o que Antonio Candido denomina fúria de urdir, em Teixeira e Sousa, e Hélio Guimarães, volúpia da ficção, no prosador mineiro, ao tempo em que reconhecemos, no trabalho desse último escritor e nas traduções intersemióticas, ou adaptações de sua produção, o fato de, ao lado da emoção teatral melodramática, ter corrido:

O drama caudaloso das relações entre negros, brancos e mulatos, livres e escravos, ricos e miseráveis no Brasil escravocrata. Esse olhar atento para a realidade, combinado com a espontaneidade $\mathrm{e}$ o impulso quase irrefreável de narrar, mantém o interesse das histórias do romancista da abolição, que continua a conquistar leitores (além de radiouvintes, espectadores e telespectadores) mundo a fora (GUIMARÃES, Op. Cit., p. XIII). 


\section{REFERÊNCIAS}

BORGES, Renata Farhat. Clássicos em HQ. Acesso em 27 jul. 2017. Disponível em: $<$ http://www.editorapeiropolis.com.br/arquivos/classicosemhq.pdf $>$.

CADEMARTORI, Lígia. Arrojos e clausuras - Prefácio a $O$ seminarista. GUIMARÂES, Bernardo. São Paulo: FTD, 1997.

CITELLI, Adilson. Linguagem e persuasão. São Paulo: Ática, 1989.

D’ANGELO, Luisa Bertrami. Adaptação de Crime e castigo para os quadrinhos. Acesso em 27 jul. 2017. Disponível em: <http://notaterapia.com.br/2016/08/30 /confira-8-imagens-sensacionais-da-adaptacao-de-crime-e-castigo-para-osquadrinhos $>$.

GUIMARÃES, Hélio de Seixas. "Entre lendas e romances, o conto de Bernardo Guimarães". Introdução. In: GUIMARÂES, Bernardo. Lendas e romances. São Paulo: Martins Fontes, 2006.

JOSEF, Bella. O jogo mágico. Rio de Janeiro: José Olympio, 1980.

PASSOS, Marie-Helénè Paret. Da criação genética à tradução literária: uma interdisciplinaridade. Vinhedo: Horizonte, 2011.

PEIRCE, Charles Sanders, Semiótica. Trad. José Teixeira Coelho Neto. $2^{\mathrm{a}}$ ed. São Paulo: Perspectiva, 1995.

PLAZA, Julio. Tradução intersemiótica. São Paulo: Perspectiva, 2003.

XAVIER, Nilson. Teledramaturgia: novelas - A escrava Isaura: bastidores. In: $<$ http://www.teledramaturgia.com.br/novelas/novelas-ordem-alfabetica $>$. Acesso em 17 mar. 2017.

Hugo Lenes Menezes HugoMenezes@ifpi.edu.br

Recebido em: 21/9/2017

Aceito em: 12/2/2018

Publicado em Abril de 2018 